Review Article

\title{
A Meta Analysis on the Ethnic Differences in Bone Mineral Density on DEXA Scan in Pakistan
}

\author{
Fatima Rehman, Sanum Ali
}

\begin{abstract}
OBJECTIVE: To determine the association of ethnic variations with the bone mineral density on Dual Energy X-ray Absorptiometry (DEXA) scan by using a database literature search.

METHODOLOGY: This study was done at the department of Anatomy, Basic Medical Sciences Institute (BMSI), Jinnah Postgraduate Medical Center (JPMC) Karachi. A systemic literature search was carried out for the publications printed in between 2000-2017, dealing with the comparison of BMD on DEXA scan among various ethnicities of Pakistan. A total of 3 cross sectional studies, having 1232 subjects ( $n=421$ males and $n=811$ females) enrolled, were found in the literature search and met the inclusion criteria. The BMD was assessed on DEXA by using Hologic model focused at the lumbar spine and neck of femur.

RESULTS: Results were displayed as $\mathrm{T}$ scores and were statistically significant. Among 1232 subjects, 690 were Punjabi (56\%), Osteopenia was found in $41.2 \%$ and osteoporosis in $25.8 \%(P$-value=0.001), 198 $(16 \%)$ were Pathan, among them $31.8 \%$ were osteopenic and $39.9 \%$ were osteoporotic $(P$-value $=0.001)$. Sindhi were $78(6.33 \%), 16.7 \%$ had osteopenia and $47.4 \%$ had osteoporosis (P-value= 0.001$) .54(4.38 \%)$ subjects were Balochi, among them $16.7 \%$ had osteopenia and $50.0 \%$ had osteoporosis $(P$-value $=0.001)$. Others ethnicities were $212(17.20 \%), 40.6 \%$ were found to be osteopenic and $34.8 \%$ had osteoporosis (P -value $=0.001$ ).

CONCLUSION: Significant variations exist in the BMD scores among various ethnicities of Pakistan. Further research is highly suggested on larger scale based upon the ethnic and regional localization, as it directly influences and indicates a predictive relationship between low bone mass and increase risk of fracture.
\end{abstract}

KEY WORDS: Bone Mineral Density, Ethnicity, Osteoporosis

This article may be cited as: Rehman F, Ali S. A Meta Analysis on the Ethnic Differences in Bone Mineral Density on DEXA Scan in Pakistan. J Liaquat Uni Med Health Sci. 2019;18(01):01-5. doi: 10.22442/jlumhs.191810592

\section{INTRODUCTION}

Bone mineral density (BMD) is a measure of mineral content of the bone, reflecting the strength of the osseous tissue. This measurement can be done by using a specialized technique called dual energy X-ray absorptiometry (DEXA) scan. The most relevant description of DEXA scan is by using the T-score ${ }^{1}$. DEXA scan was first introduced in 1987, and have proved to be an important and most validated tool for the measurement of BMD, patients who are at risk of osteoporosis and osteoporotic fractures can be identified and evaluated ${ }^{2}$ through this technique.

Osteoporosis is a considerable health hazard, characterized by decreased BMD in bones associated with structural collapse and a higher risk of fractures. It makes the bones brittle which are liable to fracture. It is a chronic disorder and is associated with significant morbidity and affects the quality of life $^{3}$.

It is estimated that there is a global prevalence of over 200 million cases of osteoporosis and are increasing day by day affecting more commonly the elderly population $^{4}, 9.9$ million of Pakistani population is suffering from osteoporosis, among which females are predominating by 7.2 million $^{5}$. About 9.0 million of osteoporotic fractures have been reported in the year 2000 alone $^{6}$.

These osteoporotic fractures are directly associated with the degree of bone strength. By measuring the BMD on DEXA scan, the individuals can be identified, who are at risk of developing fractures in the future ${ }^{7}$.

The composition of the body varies greatly in relation to the age, sex, ethnic background and is also associated with disparity in the bone structure and BMD in the adult population ${ }^{8}$. Pakistan has a rich multicultural background with an intermixture of population belonging to different ethnicities and races on the basis of their distinctive dialects, customs and regional localizations ${ }^{9}$. These ethnic and racial variations are also reflected upon their skeletal structures and composition of bones as well as they have an impact upon the periosteal and endosteal 
linings of the bone during the process of bone resorption and formation ${ }^{10}$.

A number of reports and articles have been published on the measurement of BMD on DEXA scan, but limited data is available on the ethnic variations of BMD on DEXA scan regionally as well as globally. Therefore, the current meta-analysis is aimed to gather the exact and precise knowledge in order to investigate that whether there is an association between the BMD scores in different ethnic groups of Pakistan.

\section{METHODOLOGY}

A systemic literature search was carried out for publications dealing with the comparison of BMD on DEXA scan among the various ethnic groups in Pakistan. The articles and abstracts published in the English language literature between the period 2000 and 2017 were included. Electronic databases were used for the literature search that included Google scholar, PubMed central and Pak Medinet (for non-indexed Pakistani journals).

The following keywords were used alone or in combination for literature search i.e: bone mineral density, bone mineral content, low bone mass, osteopenia, ethnic differences, racial differences, DEXA scan. All the relevant and appropriate research articles showing the Pakistani data were included. The references cited with in the articles were also carefully combed to get any relevant data.

The inclusion criteria for the current study were as follow: (1) Studies published and indexed in between January 2000 and December 2017 (2) Adult male and females (mean study age $\geq 59$ year) (3) BMD measured on DEXA scan (4) Subjects belonging to different ethnic groups of Pakistan. Only studies that met the above mentioned inclusion criteria were included in the analysis.

A total of 3 cross sectional studies have fulfilled the standard and they have calculated the BMD on DEXA scan at lumbar spine and neck of femur, following the guidelines given by $\mathrm{WHO}$ and International Osteoporotic foundation. Results were displayed as T-scores, which were further classified as normal $(\geq 1)$, osteopenia (-1.1 to -2.5$)$ and osteoporosis $(\leq 2.5)$. The selected studies are shown in Table I.

\section{RESULTS}

All the data were analyzed on SPSS version 19.0 and P-value $<0.05$ was considered significant. A total of 1232 subjects were enrolled in the selected studies for meta-analysis. Out of them 421(34.2\%) were males and $811(65.8 \%)$ were females. The average age \pm S.D was $59.78 \pm 10.3$.

Among these 1232 subjects, $382(31.0 \%)$ had normal BMD scores, $455(36.9 \%)$ subjects were identified as osteopenic showing decreased bone mass while 395 $(32.1 \%)$ had osteoporosis i-e the fragile bones. The results of BMD on DEXA scan among various ethnic groups were found to be very significant.

A total of 690 (56\%) Punjabi were enrolled in the studies, among which 228 (33.0\%) had normal BMD scores, $284(41.2 \%)$ had osteopenia and $178(25.8 \%)$ had osteoporosis (P-value=0.001). $198 \quad(16 \%)$ subjects were Pathan, normal BMD was found in 56 $(28.3 \%)$, osteopenia in $63(31.8 \%)$ and osteoporosis in $79(39.9 \%)$ of Pathan population (P-value $=0.001)$.

Sindhi population enrolled in the studies were 78 $(6.33 \%), 28(35.9 \%)$ had normal scores of BMD, 9 $(16.7 \%)$ had osteopenia and $37(47.4 \%)$ had osteoporosis (P-value $=0.001)$.

About 54 subjects were Balochi, 18 (33.3\%) had normal BMD, $9(16.7 \%)$ were osteopenic and 27 $(50.0 \%)$ had osteoporosis (P-value $=0.001)$.

Other minor ethnicities subjects enrolled were 212 $(17.20 \%)^{12,15}$, normal BMD scores were found in 52 (23.5\%), 86 (40.6\%) had osteopenia and 74 (34.8\%) were osteoporotic(P-value $=0.001)$. Results showing the association of BMD with ethnicity are shown in Table II and Figure I.

The results were highly comparable in between the different ethnicities of Pakistan. Osteopenia was significantly higher in Punjabi (41.2\%) and other minor ethnic groups $(40.6 \%)$ as compared to Pathan (31.8\%), Sindhi (16.7\%) and Balochi (16.7\%) (P-value $<0.05)$.

Osteoporosis was significantly higher in Balochi $(50.0 \%)$ followed by Sindhi $(47.4 \%)$ as compared to Pathan (39.9\%), others including Urdu speaking and Kashmiri (34.8\%) and Punjabi (25.8\%) (P-value $<0.05)$.

TABLE I: BASIC CHARACTERISTICS OF THE SELECTED STUDIES

\begin{tabular}{|l|c|c|c|c|}
\hline First author & $\begin{array}{c}\text { Year of } \\
\text { Publica- } \\
\text { tion }\end{array}$ & $\begin{array}{c}\text { Sample } \\
\text { size }\end{array}$ & Gender & Mean age \\
\hline $\begin{array}{l}\text { Uzma } \\
\text { Akhlaque }^{11}\end{array}$ & 2015 & 400 & $\begin{array}{r}\mathrm{M}=142 \\
\mathrm{~F}=258\end{array}$ & $59.24 \pm 10$ \\
\hline $\begin{array}{l}\text { Noreen } \\
\text { Akhter \& } \\
\begin{array}{l}\text { Uzma } \\
\text { Akhlaq }\end{array}\end{array}$ & 2017 & 600 & $\begin{array}{l}\mathrm{M}=253 \\
\mathrm{~F}=347\end{array}$ & $60.5 \pm 10$ \\
\hline $\begin{array}{l}\text { Saima Athar } \\
\text { Shaikh }^{10}\end{array}$ & 2017 & 232 & $\begin{array}{c}\mathrm{M}=26 \\
\mathrm{~F}=206\end{array}$ & $59.62 \pm 10$ \\
\hline
\end{tabular}


TABLE II: ASSOCIATION OF BONE MINERAL DENSITY WITH ETHNICITY

\begin{tabular}{|c|c|c|c|c|c|}
\hline & \multirow{2}{*}{ No. of subject } & \multicolumn{3}{|c|}{ Bone Mineral Density (BMD) } & \multirow{2}{*}{ P-value } \\
\hline & & Normal & Osteopenia & Osteoporosis & \\
\hline \multicolumn{6}{|c|}{ Ethnicity } \\
\hline Overall & 1232 & $382(31.0 \%)$ & $455(36.9 \%)$ & $395(32.1 \%)$ & \\
\hline Punjabi & 690 & $228(33.0 \%)$ & $284(41.2 \%)$ & $178(25.8 \%)$ & 0.001 \\
\hline Pathan & 198 & $56(28.3 \%)$ & $63(31.8 \%)$ & $79(39.9 \%)$ & 0.001 \\
\hline Sindhi & 78 & $28(35.9 \%)$ & $13(16.7 \%)$ & $37(47.4 \%)$ & 0.001 \\
\hline Balochi & 54 & $18(33.3 \%)$ & $9(16.7 \%)$ & $27(50.0 \%)$ & 0.001 \\
\hline Others & 212 & $52(23.5 \%)$ & $86(40.6 \%)$ & $74(34.8 \%)$ & 0.001 \\
\hline \multicolumn{2}{|l|}{ P-value } & 0.548 & 0.001 & 0.001 & \\
\hline
\end{tabular}

FIGURE I: VARIATION IN BONE MINERAL DENSITY ON DEXA SCAN AMONG DIFFERENT ETHNICITIES OF PAKISTAN

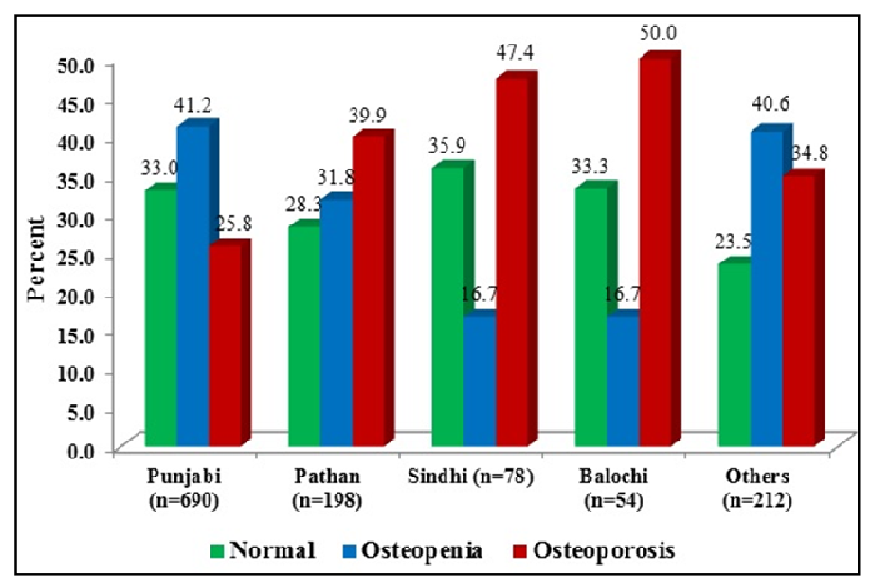

\section{DISCUSSION}

Osteoporosis is a serious health hazard affecting the elderly population more frequently. This disease is prevalent in both developed as well as in the developing nations and the affected individuals suffer from significant morbidity that can be later progress into complete immobilization.

There's a rapid increase in the annual growth rate in Pakistan and therefore the number of elderly population is also increasing. Osteoporosis is recognized as notable issue by the health care providers and is found to be associated with racial and ethnic differences ${ }^{13}$. Many comparative studies have been done in different parts of the world which signifies the variation in the BMD among various racial and ethnic groups $^{14}$.

The current meta-analysis was done on three cross sectional studies that were conducted in different parts of Pakistan and have covered multiple ethnic groups.
An association among the ethnicity and densitometry results was seen by comparing the BMD scores at the region of lumbar spine and the neck of femur in people belonging to different racial origin.

Akhlaque $U 2015^{11}$ have conducted a study to see the frequency of decreased bone mass in multi ethnic groups of Pakistan and found out that majority of the Punjabi population is suffering from osteopenia. These findings are consistent with the results of the present study in which $41.2 \%$ of the Punjabi subjects are having a low bone mass (Table II, Fig I). Other minor ethnicities like Urdu speaking and Kashmiri were falling next to Punjabi in having osteopenia. This finding was comparable to the results given by Akhlaque $U 2017^{12}$ and Baig L 2009 ${ }^{15}$. The later study was conducted in Karachi, a city having majority of Urdu speaking population ${ }^{16}$. Osteopenia decreases the mineral content of bone and makes it porous. The increased porosity aggravates the chances of bone fractures and can lead to transient or permanent deformity thus affecting the quality of life ${ }^{17}$.

The frequency of osteoporosis was most highly seen among the Balochi population, $50 \%$ of the Balochi subjects in the selected studies were found to be osteoporotic (Table II, Fig I). These results were comparable to the study conducted by Akhlaque $U$ $2015^{11}$. A research was done by Shaikh SA $2017^{10}$ in which they compared the BMD at the neck of femur and found significant osteoporosis in Sindhi as compared to other ethnicities and have described it possibly due to the insufficient intake of milk and milk products, lack of physical activity and lifestyle differences. This result is comparable to our study, in which majority of Sindhi population has osteoporosis. The possible causes of osteopenia and osteoporosis among the various ethnicities could be insufficient sun 
exposure due to traditional clothing style, low levels of Vitamin D deficiency and lack of awareness at primary care physician level, especially among the females ${ }^{18}$. The average age of world's population is increasing at an alarming rate. This rise in the geriatric community is going to create new challenges to be faced by the health care providers. According to a study Pakistan has found to be the world's $6^{\text {th }}$ most populous country having $6 \%$ of the total population aged 65 year or older and this percentage is increasing day by day ${ }^{19}$. Aging is a natural phase of life and it requires more emotional and physical support and care. Osteoporosis and its related fractures are found to be substantial health hazard for the elderly population. It can impose significant morbidity, altered quality of life and even death of the affected individuals. Estimation of the burden of disease by comparing the BMD scores in different ethnic groups and their association with age is the current need of the day.

Very few studies showing the correlation between the ethnicities and BMD was found to be the limitation in the current study. Future researches are required on extensive grounds that must include the nutritional status, socio economic conditions, physical activity and cultural preferences that altogether affect the bone health between the ethnic groups in different age group strata.

\section{CONCLUSION}

Significant variations exist in the BMD scores among various ethnicities of Pakistan. Further research is highly suggested on larger scale based upon the ethnic and regional localization, as it directly influences and indicates a predictive relationship between low bone mass and increase risk of fracture.

\section{CONFLICT OF INTEREST}

No conflict of interest has been declared by any author in the current study.

\section{REFERENCES}

1. Fawzy T, Muttappallmyalil J, Sreedharan J, Ahmed A, Alshamsi SO, Al Ali MS, et al. Association between body mass index and bone mineral density in patients referred for Dual Energy $X$ ray Absorptiometry scan in Ajman, UAE. J Osteoporos. 2011; 2011:876309. doi: $10.4061 / 2011 / 876309$.

2. Blake GM, Fogelman I. The role of DXA bone density scans in the diagnosis and treatment of osteoporosis. Postgrad Med J. 2007; 83(982):509-
517. doi: 10.1136/pgmj. 2007.057505

3. Kling JM, Clarke BL, Sandhu NP. Osteoporosis Prevention, screening and treatment: A review. J Womens Health (Larchmt). 2014; 23(7):563-572. Doi: 10.1089/jwh.2013.4611.

4. Reginster JY, Burlet N. Osteoporosis: A still increasing prevalence. Bone. 2006; 38(2 Suppl 1): S4-S9.

5. Nagi D, Butt Z, Farooq F, Aamir A. Frequency of osteoporosis in an ambulatory setting in Lahore using quantitative calcaneal ultrasound. JPMA. 2013; 63(8): 965-968.

6. Johnell O, Kanis JA. Anestimate of the worldwide prevalence and disability associated with osteoporotic fractures. Osteoporos Int. 2006; 17 (12):1726-1733.

7. Marshall $\mathrm{D}$, Johnell $\mathrm{O}$, Wedel $\mathrm{H}$. Meta-Analysis of how well measures of bone mineral density predict occurrence of osteoporotic fractures. BMJ. 1996; 312(7041):1254-9.

8. Zengin A, Prentice A, Ward KA. Ethnic differences in bone health. Front Endocrinol. 2015; 6:24. doi: 10.3389/fendo.2015.00024

9. Bhattacharya S. Pakistan's ethnic entanglement. JSPES. 2015; 40 (3): 231-62.

10. Shaikh SA, Iqbal J, Faisal L, UI Islam Z, Ajmal R. Difference in bone mineral density score on dual X-ray absorptiometry scan among ethnic groups of Karachi, Pakistan. RMJ. 2017; 42(4):484-489.

11. Akhlaque $U$, Ahmad $\mathrm{K}$, Ahmed $\mathrm{N}$, Waheed $\mathrm{A}$, Akhter N. Frequency of low bone mass in a cohort of mixed Pakistani population. Pak Armed Forces Med J. 2015; 65(3):323-327.

12. Akhlaque U, Ayaz SB, Akhter N, Ahmed N. Association of bone mineral density and body mass index in a cohort of Pakistanis: Relation to gender, menopause and ethnicity. Egyptian Rheumatol. 2017; 39:39-43.

13. Int Osteopososis Foundation. The Asian audit Epidemiology, costs and burden of osteoporosis in Asia 2009. pp. 40-42. Available from: https:// www.iofbonehealth.org/ sites/default/files/PDFs/ Audit\%20Asia/Asian_regional_audit_2009.pdf.

14. Cauley JA. Defining ethnic and racial differences in osteoporosis and fragility fractures. Clin Orthop Relat Res. 2011; 469(7):1891-1899. doi: 10.1007/ s11999-011-1863-5

15. Baig L, Mansuri FA, Karim SA. Association of menopause with osteopenia and osteoporosis: Results from population based study done in Karachi. J Coll Physicians Surg Pak. 2009; 19 
(4):240-244. doi: 04.2009/JCPSP.240244.

16. Pakistan Population. (2018-09-24). Retrieved 2019-02-14, from http://worldpopulation review.com/countries/pakistan/

17. Almeida M, Laurent MR, Dubois V, Claessens F, O'Brien CA, Bouillon R, et al. Estrogens and androgens in skeletal physiology and pathophiology. Physiol Rev. 2017; 97(1):135-187

18. Majeed MZ, Saeed M, Manzur A. Frequency and risk factors for serum vitamin $D$ deficiency among females of Pakistan. JSZMC. 2014; 5(2):622-626.

19. Ashiq $U$, Asad $A Z$. The rising old age problem in Pakistan. J Res Soc Pak. 2017; 54(2): 325-33.

AUTHOR AFFILIATION:

Dr. Fatima Rehman (Corresponding Author)

Department of Anatomy

Basic Medical Sciences Institute

Jinnah Post Graduate Medical Centre

Karachi, Sindh-Pakistan.

Email: fatimakureshi@hotmail.com

Dr. Sanum Ali

Department of Anatomy

Basic Medical Sciences Institute

Jinnah Post Graduate Medical Centre

Karachi, Sindh-Pakistan. 